\title{
Erratum to: S-wave attenuation in northeastern Sonora, Mexico, near the faults that ruptured during the earthquake of 3 May $1887 \mathrm{Mw} 7.5$
}

Gina P Villalobos-Escobar ${ }^{1,2^{*}}$ and Raúl R Castro ${ }^{1}$

\section{Erratum}

In the original version of this article (Villalobos-Escobar and Castro 2014), Figures 6, 7, and 8 were marked up incorrectly. Figure 6 should show examples of nonparametric attenuation functions, instead the incorrect Figure 6 shows values of the exponent $b$ of the geometrical spreading function (equation 4) and estimates of the quality factor $Q$. Figure 7 should show attenuation functions scaled according to event 9 (Table 1) which is an $\mathrm{M}=3.5$ earthquake. Instead, the incorrect Figure 7 printed shows estimates of $Q$ obtained by other authors and those obtained in this study. Figure 8 is also incorrect; this figure should show the values of $b$ and $Q$ displayed in the printed Figure 6.

In this erratum, the corrected Figures 6, 7, and 8 are shown as Figure 1, Figure 2, and Figure 3, respectively.

\section{References}

Villalobos-Escobar GP, Castro RR (2014) S-wave attenuation in northeastern Sonora, Mexico, near the faults that ruptured during the earthquake of 3 May 1887 Mw 7.5. SpringerPlus 3:747

\footnotetext{
*Correspondence: villalobos@geociencias.unam.mx

${ }^{1}$ Centro de Investigación Científica y de Educación Superior de Ensenada (CICESE), División Ciencias de la Tierra, Departamento de Sismología, Carretera Ensenada-Tijuana No. 3918, Ensenada, Baja California 22860, México ${ }^{2}$ Present address: Centro de Geociencias, Universidad Nacional Autónoma de México (UNAM), Blvd. Juriquilla No. 3001, Querétaro 76230, México
} 

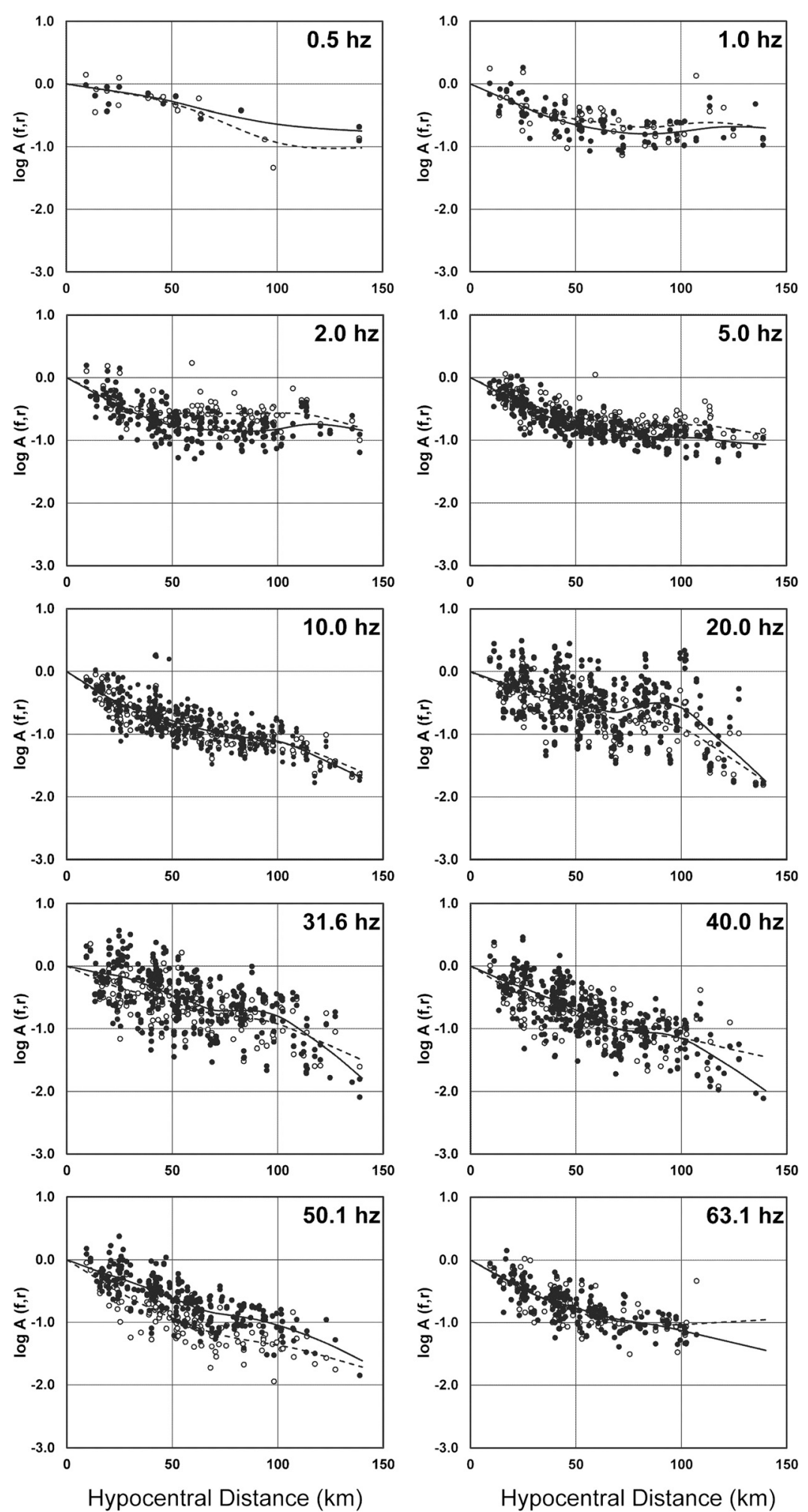

Figure 1 Examples of nonparametric attenuation functions obtained for 10 different frequencies. Black circles are observed horizontal S-wave spectral amplitudes for all magnitudes, open circles are observed vertical S-wave spectral amplitudes for all magnitudes. Black continuous line corresponds to the attenuation function found for the horizontal spectral amplitudes $\left(\mathrm{cm} / \mathrm{s}^{2}\right)$ and dashed line corresponds to the attenuation function found for the vertical component of the acceleration spectral amplitudes $\left(\mathrm{cm} / \mathrm{s}^{2}\right)$. This is the corrected Figure 6 in Villalobos-Escobar and Castro (2014). 

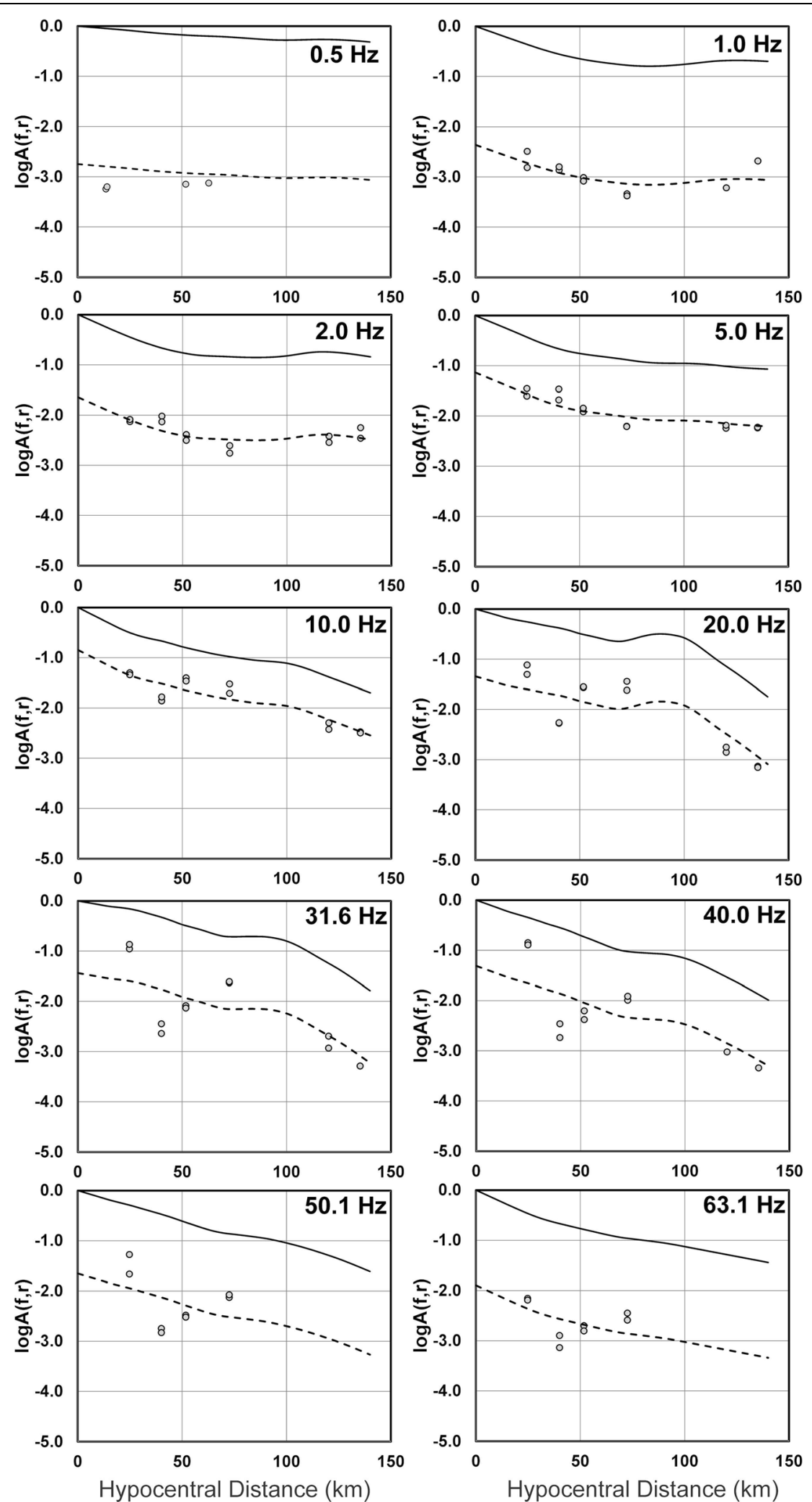

Figure 2 Attenuation functions obtained for event $\mathbf{9}\left(M_{L}=3.5\right)$ for 10 of the $\mathbf{2 3}$ frequencies studied. The dots are the observed horizontal spectral amplitudes of event 9, continuous line represents the un-scaled attenuation function and the dashed line represents the attenuation function scaled by its respective source-size factor. This is the corrected Figure 7 in Villalobos-Escobar and Castro (2014). 

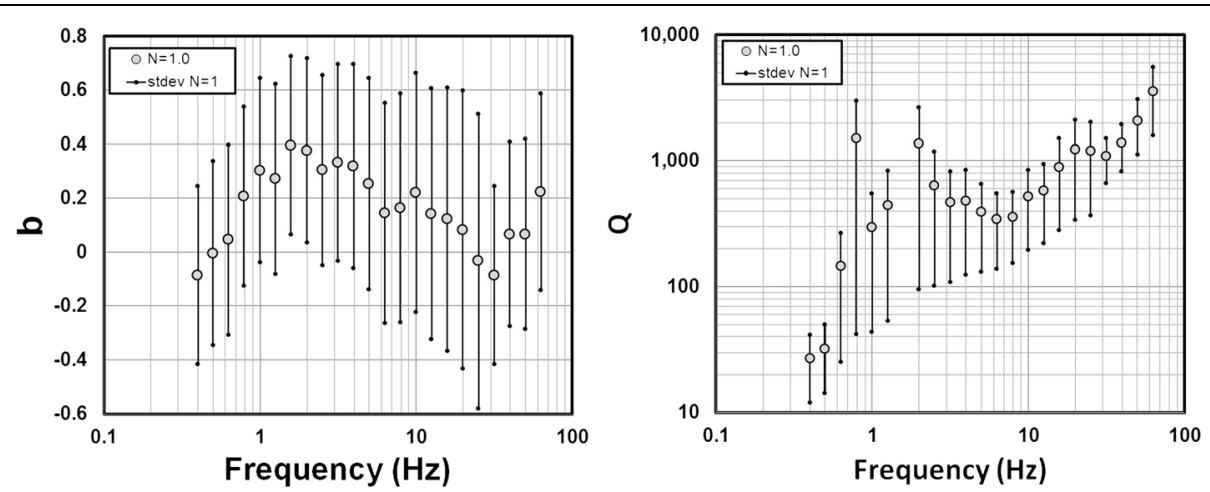

Figure 3 Estimates of $b$ (left frame) and $Q$ (right frame) for $N=1.0$ (see equation (4)) for the whole hypocentral distance range (10-140km). This is the corrected Figure 8 in Villalobos-Escobar and Castro (2014). 